\title{
A saúde mental em tempos de desafios e retrocessos: uma revisão
}

\author{
Mental health in times of challenges and setbacks: a review
}

Lara Rodrigues CAPUTO*

https://orcid.org/o00o-0002-5782-0355

Marciléa TOMAZ**

https://orcid.org/oooo-0003-2388-6409

\section{Vanisse Bernardes BEDIM ${ }^{* * *}$}

https://orcid.org/oooo-0002-0646-6042

\section{Marco José de Oliveira DUARTE**** \\ https://orcid.org/oooo-0002-6395-1941}

Resumo: O presente artigo trata de uma revisão integrativa acerca do tema saúde mental, em tempos de desafios e retrocessos, nas revistas brasileiras da área do Serviço Social. Apresenta-se o contexto histórico da Reforma Psiquiátrica brasileira até o momento presente. Em seguida, para a revisão integrativa, partese dos dados obtidos através da seleção das revistas da área, centrando-se em seis delas: Serviço Social \& Sociedade, Katálysis, Revista de Políticas Públicas, Argumentum, Textos \& Contextos e O Social em Questão, utilizando-se os seguintes descritores: saúde mental, políticas públicas, tendências e retrocessos, analisando, portanto, dezesseis artigos. As análises focam o desmonte da política pública de saúde mental, álcool e outras drogas, diante do contexto de acirramento da crise do Estado neoliberal e da emergência do neoconservadorismo, colocando em questão os desafios de resistência ao seu enfrentamento.

Palavras-chave: Saúde Mental. Políticas Públicas. Revisão Integrativa. Retrocessos.

Abstract: This article is an interrogative review of articles in Brazilian magazines on the area of Social Work around the theme of mental health in times of challenges and setbacks. It sets out the historical context of the Brazilian Psychiatric Reform to date. Then, for the interrogative review, it starts with data

\footnotetext{
* Assistente Social. Especialista em Saúde Mental. Mestranda do Programa de Pós-Graduação em Serviço Social da Universidade Federal de Juiz de Fora (UFJF, Juiz de Fora, Brasil). Rua José Lourenço Kelmer, s/n, São Pedro. Juiz de Fora (MG), CEP: 36.036-90o. E-mail: lararrcaputo@gmail.com.

** Assistente Social. Especialista em Saúde Mental. Mestranda do Programa de Pós-Graduação em Serviço Social da Universidade Federal de Juiz de Fora (UFJF, Juiz de Fora, Brasil). Rua José Lourenço Kelmer, s/n, São Pedro. Juiz de Fora (MG), CEP: 36.036-90o. E-mail: marcilea.jf@gmail.com.

*** Assistente Social. Especialista em Saúde Mental. Mestranda do Programa de Pós-Graduação em Serviço Social da Universidade Federal de Juiz de Fora (UFJF, Juiz de Fora, Brasil). Rua José Lourenço Kelmer, s/n, São Pedro. Juiz de Fora (MG), CEP: 36.036-90o. E-mail: vanissebbedim@gmail.com.

${ }^{* * * *}$ Assistente Social. Pós-Doutor em Políticas Sociais. Docente Colaborador do Programa de PósGraduação em Serviço Social da Universidade do Estado do Rio de Janeiro. Professor Adjunto da Faculdade de Serviço Social e Docente Permanente do Programa de Pós-Graduação em Serviço Social da Universidade Federal de Juiz de Fora (UFJF, Juiz de Fora, Brasil). Rua José Lourenço Kelmer, s/n, São Pedro. Juiz de Fora (MG), CEP: 36.036-90o. E-mail: majodu@gmail.com.
} copiar e redistribuir o material em qualquer suporte ou formato, bem como adaptar, transformar e criar a partir deste material para qualquer fim, mesmo que comercial. O licenciante não pode revogar estes direitos desde que você respeite os termos da licença. 
obtained from a selection of magazines in the area, focusing on six of them: Serviço Social \& Sociedade, Katálysis, Revista de Políticas Públicas, Argumentum, Textos \& Contextos and O Social em Questão. Using the following descriptors: mental health, public policies, trends, and setbacks, it analyses sixteen articles. The analysis focuses on the dismantling of public policies on mental health, alcohol, and other drugs, in the context of the worsening crisis of the neoliberal state and the emergence of neoconservatism and questions the challenges of the resistance to confronting it.

Keywords: Mental health. Public policy. Integrative Review. Setbacks.

Submetido em: 31/3/2020. Revisado em: 5/7/2020. Aceito em: 7/7/2020.

\section{Introdução}



presente artigo tem como objetivo apresentar um balanço geral da política de saúde mental, dando ênfase aos desafios enfrentados na atualidade. Realiza-se uma breve contextualização da Reforma Psiquiátrica, o momento atual e, por fim, apresenta-se a pesquisa de revisão integrativa realizada em 6 (seis) revistas da área de Serviço Social, sendo cinco, atualmente, avaliadas pela Coordenação de Aperfeiçoamento de Pessoal de Nível Superior (CAPES), do Ministério da Educação, no Qualis-Periódicos ${ }^{1}$, como A1 e uma como A2. São elas: Argumentum, Katálysis, Serviço Social E Sociedade, Políticas Públicas, Textos E Contextos e O Social em Questão.

A revisão integrativa (JACKSON, 1980; SOUZA; SILVA; CARVALHO, 2010) consiste em 5 fases: a elaboração de pergunta norteadora, no caso, como se deram os retrocessos no campo da saúde mental brasileira?; em seguida, a busca nas bases de dados, utilizandose os periódicos acima; na terceira fase, análise crítica dos conteúdos apresentados nos artigos selecionados; na quarta fase, discussão dos resultados, ou seja, os temas abordados no último tópico deste artigo e, na quinta e última fase, apresentação da revisão integrativa. Ressalta-se que

[...] a revisão integrativa, finalmente, é a mais ampla abordagem metodológica referente às revisões, permitindo a inclusão de estudos experimentais e nãoexperimentais para uma compreensão completa do fenômeno analisado. Combina também dados da literatura teórica e empírica, além de incorporar um vasto leque de propósitos: definição de conceitos, revisão de teorias e evidências, e análise de problemas metodológicos de um tópico particular (SOUZA; SILVA; CARVALHO, 2010, p. 103).

O recorte temporal definido foi a utilização de artigos publicados entre janeiro de $200 \mathbf{1}^{2}$ a janeiro de 2020, levando em consideração a aprovação da Lei no 10.2016 (BRASIL, 2001) e o primeiro ano do governo Bolsonaro. Os critérios de inclusão foram os artigos que abordavam como tema principal os avanços e retrocessos no campo da saúde mental brasileira. Já os critérios de exclusão giraram em torno de artigos que não apresentavam relação com a temática saúde mental; artigos que abordavam questões específicas da área de saúde mental, sem apresentar, como objetivo principal, os retrocessos

\footnotetext{
${ }^{1} \mathrm{O}$ Qualis-Periódicos é uma ferramenta usada para classificar a produção científica dos programas de pós-graduação no que se refere aos artigos publicados em periódicos científicos e é baseado nas informações fornecidas pois tais programas através da Plataforma Sucupira. A classificação, realizada pelas respectivas áreas científicas, a partir de 2019, apresenta-se em A1; A2; A3; A4; B1; B2; B3; B4; e C. ${ }^{2}$ Ressalta-se que as revistas Argumentum e Textos \& Contextos apesar de terem suas publicações após o recorte inicial proposto, a primeira, em 2009 e a segunda, em 2002, ambas revelam, em suas publicações na área, análises da política pública em tela.
} 
enfrentados no recorte pesquisado; e artigos que não tratavam, especificamente, do contexto brasileiro. Os descritores utilizados foram: saúde mental, políticas públicas, tendências e retrocessos, de forma articulada e combinada.

\section{A constituição histórica do processo da Reforma Psiquiátrica brasileira}

Amarante e Nunes (2018), Tenório (2002) e Duarte (2018), entre outros autores, apresentam um balanço geral acerca da Reforma Psiquiátrica brasileira, trazendo os principais marcos. Apontam a gênese do movimento ocorrida na década de 1970, mais precisamente em 1978, com o surgimento do Movimento de Trabalhadores em Saúde Mental (MTSM). Este surgiu a partir da denúncia das péssimas condições de trabalho e da violência cotidiana cometida aos pacientes nas instituições psiquiátricas. A partir daí, o movimento ganhou força e apoio de organismos importantes à época, como, por exemplo, o Centro Brasileiro de Estudos da Saúde (CEBES) e o Renovação Médica (REME), tornando-se um movimento nacional em busca de mudanças significativas dos hospitais psiquiátricos e seu modelo manicomial. Sobre a gênese desse processo, Amarante e Nunes (2018) assim se manifestam:

O episódio diz respeito à mobilização de bolsistas e residentes dos hospitais psiquiátricos do Ministério da Saúde (MS), onde as condições eram absolutamente precárias. A partir de uma carta encaminhada ao Ministro da Saúde com denúncias e reivindicações, foram demitidos 260 profissionais, desencadeando um processo de novas denúncias, manifestações e matérias na imprensa durante vários meses (AMARANTE; NUNES, 2018, p. 2068).

Vale lembrar que a sociedade brasileira vivenciava um período violento na década de 1970, governada pelo regime civil-militar-empresarial (1964-1985). No entanto, no final de 1970 e início de 1980, ocorreu no país uma reorganização dos movimentos sociais, em especial, o surgimento do Movimento Sanitário em busca de uma saúde pública, integral, equânime, universal e de qualidade, trazendo para a cena política um debate acirrado acerca das políticas sociais e contribuição pela redemocratização do país.

Com o fim da Ditadura, em 1985, em seguida, em 1986, foi realizada a oitava Conferência Nacional de Saúde (CNS), sendo um marco importante para a estruturação do Sistema Único de Saúde (SUS). Como desdobramento desse evento, em 1987, ocorreu a I Conferência Nacional de Saúde Mental (CNSM), seguindo-se o direcionamento dado a partir da conferência anterior. Nesse contexto, no mesmo ano, acontece o II Encontro Nacional do MTSM, conhecido como Congresso de Bauru. O movimento ganhou novos rumos, adotando o lema conhecido como: por uma sociedade sem manicômios. Ou seja, houve uma ruptura na trajetória do MTSM, reconhecendo que não caberia apenas transformações no interior dos hospícios, mas, sim, sua efetiva extinção. Assim,

A I Conferência representa, portanto, o fim da trajetória sanitarista, de transformar apenas o sistema de saúde, e o início da trajetória de desconstruir no cotidiano das instituições e da sociedade as formas arraigadas de lidar com a loucura. É a chamada desinstitucionalização. O encontro que a ela se segue institui um novo lema: Por uma Sociedade sem Manicômios (TENÓRIO, 2002, p. 35). 
Cabe ressaltar os avanços significativos no que tange ao campo da saúde, em particular, na nova Constituição Federal, de 1988, ao ampliar o conceito e politizar a política pública, como um direito de todos e dever do Estado que, logo em 1990, ganhou materialidade com o estabelecimento do Sistema Único de Saúde (SUS), a partir das Leis no 8.080 e no 8.142, demarcando os conselhos e as conferências como mecanismos de participação e controle social.

Em 1992, na II CNSM, as críticas ao modelo asilar-hospitalocêntrico foram amadurecidas, não mais se defendendo a humanização dos manicômios, mas sim sua efetiva e progressiva extinção. Assim, considera-se a década de 1990 como a segunda trajetória da Reforma Psiquiátrica brasileira, em particular, pela implantação, de forma concreta, de novos modelos e serviços assistenciais extra-hospitalares de caráter substitutivo.

No entanto, o processo de Reforma Psiquiátrica, apesar de experiências exitosas por todo o território, se deu de forma mais lenta. Somente em 2001 foi aprovada, após mais de 10 anos de tramitação no congresso, a denominada Lei da Reforma Psiquiátrica, a Lei no 10.216/2001. Dentre seus artigos, propunha a extinção dos manicômios, modificando o projeto original, com vários substitutivos. Contudo, deixou brechas, principalmente sobre a permanência dos hospitais psiquiátricos, na medida em que "[...] o texto aprovado reflete a disputa de interesses que se colocou (e ainda se coloca) no campo da saúde mental. Dessa maneira, considera-se que a Lei no $10.216 / 2001$ apontou para a “[...] reforma psiquiátrica possível" (HEIDRICH, 2017, p. 74).

Assim, as legislações, tanto a referida lei, como as diversas Portarias do Ministério da Saúde, em particular a GM/MS № 336 (BRASI, 2002) que instituiu os Centros de Atenção Psicossocial (CAPS), posteriormente a III CNSM, em 2001, foram importantes para os avanços na saúde mental como um todo. Todavia, antes mesmo dessas conquistas legislativas, diversas experiências se desenvolveram por todo o território. Isso porque

[...] em alguns estados da federação já havia legislações específicas, pulsionadas pela militância antimanicomial, mas sem sombra de dúvida, a nova lei da saúde mental veio contribuir tanto para a diminuição dos leitos psiquiátricos, em processo de ampliação da rede substitutiva dos mesmos através dos CAPS, como em novos dispositivos assistenciais e socioculturais, como os Serviços Residenciais Terapêuticos (SRT) (BRASIL, 200o), os Centros de Convivência e Cultura, as Cooperativas de Trabalho, o trabalho protegido e os diversos projetos de economia solidária, de geração de emprego e renda e de iniciativas culturais (DUARTE, 2018, p. 231).

Apesar da definição legislativa de CAPS como centro da rede de saúde mental, esse fato foi criticado por muitos autores, uma vez que trouxe o risco de afetar a dinamicidade própria desses dispositivos. Como a assistência em saúde mental, desde o início, se configurou em experiências baseadas na criatividade e na singularidade, uma dita formatação e padronização desses dispositivos poderiam ser prejudiciais para o desenrolar dos serviços, baseados justamente em experiências particulares e criativas. 
Assim, desde 2001 considera-se uma expansão dos serviços psicossociais e o cuidado em liberdade passou a espraiar por todo o país. A exigência de 'formatação' dos serviços para cadastramento e financiamento ameaçou e ameaça a característica fundante dos serviços substitutivos que é a 'invenção' do cuidado (HEIDRICH, 2017, p. 75).

Conquanto o processo de Reforma Psiquiátrica brasileiro, notoriamente, tenha obtido muitas conquistas no decorrer dos anos seguintes, desde sua gênese, enfrentou e ainda enfrenta desafios importantes. No tópico a seguir, trataremos dos impasses vivenciados na atualidade.

\section{Tempos de retrocessos na política de saúde mental e na sociedade brasileira}

A partir de 2010, na última gestão do segundo mandato do governo Lula, desenha-se a perspectiva disjuntiva entre saúde mental e a questão de álcool e outras drogas, girando em torno de disputas pelo orçamento público de diferentes setores governamentais. Emerge o Decreto no 7.179 (BRASIL, 2010), que institui o Plano Integrado de Enfrentamento ao Crack e outras Drogas, implementado pelo Crack: é possível vencer (GUIMARÃES; ROSA, 2019). Apesar das deliberações da IV CNSM de caráter intersetorial, realizada no mesmo ano, o referido Plano é reiterado com a Portaria no 3.088 (BRASIL, 2011), que insere as Comunidades Terapêuticas (CT) como serviços de atenção residencial de caráter transitório, o que evidencia mudanças drásticas na Rede de Atenção Psicossocial (RAPS) instituída pela própria Portaria.

Ademais, é de 2015 em diante, e, especificamente, no governo da segunda gestão presidencial de Dilma Rousseff (2015-2016), que a configuração no que tange à saúde mental muda, com fortes posicionamentos conservadores, na defesa do isolamento como tratamento e da religião como cura (REVADAM; SCARTEZINI, 2020).

Não obstante, temos a nomeação de Marcelo Castro como Ministro da Saúde, em 2015, o que corroborou para os ataques dos setores conservadores à política de saúde mental, álcool e outras drogas. A Associação Brasileira de Psiquiatria (ABP), opositora ao movimento de Reforma Psiquiátrica brasileira, ganha a cena da gestão pública. Trata-se de um momento de ruptura ideológica com as históricas nomeações à CoordenaçãoGeral de Saúde Mental, Álcool e outras Drogas (CGMAD), que até então eram representados por gestores alinhados aos princípios e diretrizes da Reforma Psiquiátrica (PINHO, 2019).

É nesse contexto que se vivencia ainda mais o adensamento dos retrocessos na RAPS, pois as CT se reafirmam como estabelecimentos de saúde por meio da Portaria ㄲo $\mathbf{1 . 4 8 2}$ (BRASIL, 2016b), capacitando-as a receber recursos públicos do SUS.

Com a nova gestão federal, o governo Temer (2016-2018) deu continuidade ao desmonte de direitos no campo da saúde mental, com diminuição dos recursos para os CAPS, aumento do financiamento para as $\mathrm{CT}$ e para os hospitais psiquiátricos tradicionais, bem como a redução dos espaços de participação e controle social (REVADAM; SCARTEZINI, 2020). Uma nova política de saúde mental começa a se consolidar, num cenário cada vez mais crítico. Como enfatizado por Duarte (2018), temos o avanço da indústria farmacêutica, aumento da medicalização e da medicamentalização, enfrentamento do

Argum., Vitória, v. 12, n. 2, p. 91-106, maio/ago. 2020. | ISSN 2176-9575 
corporativismo médico, ausência de psiquiatras na rede pública de saúde mental e a atenção à crise olhada pela perspectiva da internação. Nesse ínterim, ainda temos a aprovação da Emenda Constitucional no 95 (BRASIL, 2016a), que limita por 20 (vinte) anos os gastos públicos, o que gera subfinanciamento e cortes na saúde, num cenário de contratação temporária de trabalhadores, precariedade dos serviços, e, paralelamente a isso, o refluxo dos movimentos sociais que tinham como bandeira a política de saúde mental.

Os segmentos opositores do corporativismo médico à Reforma Psiquiátrica brasileira, vinculados à $\mathrm{ABP}$, permaneceram, ideopoliticamente, a partir de 2016, com o governo Temer, mantendo a mesma condução política, marcada pelo conservadorismo e pela lógica manicomial, corroborando para muitas alterações substantivas na RAPS.

A partir de 2017, reiterando a agenda de retrocessos, o novo Ministro da Saúde, Ricardo Barros, nomeia Quirino Cordeiro Junior para exercer a gestão na CGMAD, ratificando a indústria de leitos de internação e da hegemonia do saber médico, com críticas à rede intersetorial e ao cuidado em liberdade e de base comunitária (PINHO, 2019). Desenhase uma outra política de saúde mental com a Portaria no 3.588 (BRASIL, 2017), que elenca os dispositivos da nova RAPS: equipe multiprofissional de atenção especializada em saúde mental/unidades ambulatoriais especializadas, unidade de referência especializada em hospital geral, hospital psiquiátrico especializado, hospital-dia e o CAPSad IV, com funcionamento $24 \mathrm{~h}$, com equipes multiprofissionais e que serão localizados em regiões metropolitanas, acima de 500 mil habitantes e próximos às ditas cracolândias.

Duarte (2018) faz uma análise comparativa entre a RAPS original e a modificada, o que torna relevante destacar para evidenciar as mudanças abruptas nesse cenário de retrocessos.

O quadro comparativo entre as Portarias 3.088/11 (RAPS original) e 3.588/17 (RAPS alterada) mostra o novo desenho assistencial da 'nova' política de saúde mental, incluindo o recurso institucional iatrogênico, mas sempre defendido pela corporação médico-psiquiátrica, a Associação Brasileira de Psiquiatria (ABP), com apoio do Conselho Federal de Medicina (CFM), o hospício. Reforçase a lógica manicomial com financiamento de leitos em hospitais psiquiátricos e o aumento de números de leitos em hospitais gerais, de forma que não permite o cuidado de qualidade e em liberdade, posto as internações como única alternativa de resposta à crise, retrocedendo aos típicos loucos ociosos dos manicômios (DUARTE, 2018, p. 236).

Ainda como desdobramento do governo Temer, em março de 2018, foi aprovada uma nova política de drogas no Conselho Nacional de Políticas sobre Drogas (CONAD), orientada para abstinência e não mais pela redução de danos, o que significa uma política proibicionista com foco nas internações, e, consequentemente, no fortalecimento das CT. 
Ao ser priorizado o estabelecimento de contratos/parcerias com comunidades terapêuticas, em detrimento do suporte financeiro que deveria ser ofertado aos serviços do SUS, fica suprimido o aspecto da redução de danos, colocado como primordial na execução da própria Política Nacional sobre Drogas, uma vez que as comunidades terapêuticas possuem como principal característica norteadora de sua modalidade de tratamento a precondição da abstinência, em desrespeito ao percurso e possibilidades do consumidor (ARAGÃO; ROSA, 2019, p. 230).

No ano de 2019, com o governo Bolsonaro, as políticas iniciadas anteriormente acentuaram-se e a abstinência como forma de tratamento ao uso de drogas se fortaleceu, sendo o seu foco, como também a lógica da internação compulsória.

Essa mudança implicou a reversão dos gastos públicos na área, jogando-se fora estratégias exitosas como tratamento assertivo na comunidade, de redução de danos, que implicam o cuidado contínuo e em liberdade, mesmo que o uso de drogas não tenha sido interrompido, com ênfase na prevenção e atenuação de agravos à saúde, utilizadas por dezenas de países em todo o mundo (PITTA; GULJOR, 2019, p. 12).

Na contramão das propostas da Reforma Psiquiátrica, foi emitida pela CGMAD a Nota Técnica 11 (BRASIL, 2019c), que, além de desconstruir os ganhos da Reforma, incentiva aos hospitais psiquiátricos a internação de crianças e adolescentes, o uso de eletrochoque, o atendimento ambulatorial às demandas psiquiátricas e reforço às CT.

Assim, com os setores conservadores instalados na gestão federal, institui-se a Secretaria Nacional de Cuidados e Prevenção às Drogas, através do Decreto no 9.674 (BRASIL, 2019a), no âmbito do Ministério da Cidadania. Contudo, a novidade fica com Quirino Cordeiro Junior, que passa a assumir a gestão da nova pasta, desistindo de ser o gestor da CGMAD do Ministério da Saúde. Guimarães e Rosa (2019) apontam que essa cisão na política pública sobre drogas impõe que a nova pasta assuma "[...] a área da redução da demanda e do Ministério da Justiça e Segurança Pública, gerido pelo Sérgio Moro, que ficou encarregado com a área da redução da oferta de drogas" (GUIMARÃES; ROSA, 2019, p. 129). Por outro lado, esse novo reordenamento institucional provoca uma outra cisão, mas no campo assistencial, entre as políticas de drogas e a de saúde mental, álcool e outras drogas.

É relevante ressaltar que o ano de 2019 foi seriamente marcado pela não-comunicação com os movimentos sociais. No âmbito dos conselhos de políticas e de direitos, o governo publica um decreto que estabelece a nova Política Nacional sobre Drogas (PNAD), revogando o anterior, de 2002, instituído no governo de Fernando Henrique Cardoso. Ainda assim, dois meses seguintes é sancionada a nova Lei no 13.840 (BRASIL, 2019b), em substituição à anterior, que trata do Sistema Nacional de Políticas Públicas sobre Drogas (SISNAD).

Observa-se, dessa maneira, o crescimento das CT, os hospitais psiquiátricos e hospitaisdia de cunho privado são retomados e ampliam-se de forma sistemática na sociedade. Uma política marcada fortemente pelo retorno da lógica manicomial, do proibicionismo, da violência e do moralismo, com ausência de debates com foco na cidadania, sem 
interseccionar com os marcadores sociais de desigualdades e de diferenças, como a questão de gênero, de raça e de classe social.

\section{Nos caminhos da revisão integrativa na literatura do Serviço Social sobre o debate presente da política de saúde mental}

Neste estudo foram incluídos 16 (dezesseis) artigos que atenderam aos critérios de inclusão previamente estabelecidos. A tabela abaixo apresenta os dados encontrados nos periódicos especializados da área de Serviço Social pesquisados:

\begin{tabular}{|c|c|c|c|}
\hline $\begin{array}{c}\text { Tabela 1 - Periódicos pesquisados } \\
\text { pesquisadicos }\end{array}$ & $\begin{array}{c}\text { Artigos } \\
\text { selecionados por } \\
\text { descritores }\end{array}$ & $\begin{array}{c}\text { Artigos } \\
\text { excluídos }\end{array}$ & $\begin{array}{c}\text { Artigos } \\
\text { analisados }\end{array}$ \\
\hline Argumentum & 20 & 14 & 6 \\
\hline Katálysis & 7 & 7 & 0 \\
\hline $\begin{array}{c}\text { Serviço Social \& } \\
\text { Sociedade }\end{array}$ & 0 & 0 & 0 \\
\hline Políticas Públicas & 5 & 2 & 3 \\
\hline Textos \& Contextos & 5 & 3 & 2 \\
\hline O Social em Questão & 14 & 9 & 5 \\
\hline Total Geral & 51 & 35 & 16 \\
\hline
\end{tabular}

Fonte: Elaboração dos autores.

Dos 16 (dezesseis) artigos analisados sobre o assunto em questão, percebeu-se, nesta pesquisa, que 4 (quatro) deles foram publicados em 2015; 3 (três) em 2017; 5 (cinco) em 2018 e 4 (quatro) em 2019. Em relação ao tipo de metodologia aplicada, registra-se a análise qualitativa, com foco na revisão de literatura.

Assim, apesar de a pesquisa tomar como recorte temporal de publicação o período de 2001-2020, os estudos relacionados à política pública de saúde mental, álcool e outras drogas, relacionando-se com as tendências e retrocessos identificados, demarcam o ano de 2015 como marco em que se deu o crescimento do conservadorismo e das práticas desmanteladoras da Reforma Psiquiátrica brasileira, tendo, como referência de resistência ao desmonte, a ocupação Fora Vallencius, por militantes da luta antimanicomial de todo o país, no governo de Dilma Rousseff.

A despeito desse fato, não foi possível controlar o avanço privatista e manicomial em curso. Segundo Duarte (2018), houve um golpe dentro do golpe, tratando-se, nesse contexto, da contrarreforma da saúde mental, com a radicalização dos setores conservadores, no ano seguinte, com o governo de Michel Temer, sua base de sustentação, incluindo, nessa, o corporativismo médico, que organiza a nova política de saúde mental.

Dessa forma, os artigos referentes ao ano 2015 tratam do contexto da crise capitalista, das implicações para o setor da saúde, mediante a redução do Estado, no qual incide diretamente a condução da política em análise. Silva e Moura (2015) apontam a necessidade da reflexão acerca da abordagem atual da política, tendo em vista os rebatimentos do ajuste neoliberal. Nesse sentido, um dos maiores desafios para a saúde mental, em particular, para os princípios da Reforma, são as tendências à privatização 
da saúde, visto o estímulo à precarização dos serviços sociais e a busca de soluções no setor privado.

O atual contexto neoliberal, com perspectivas neoconservadoras, possibilitou aberturas para os capitalistas obterem mais lucros, como na prevalência do saber-poder médico, na expansão da indústria farmacêutica e no incentivo ao tratamento centrado em hospitais psiquiátricos. Nesse contexto, a lógica manicomial ainda se faz presente. Os cuidados em saúde mental são atravessados não apenas pela questão orçamentária, mas por essa lógica. Um exemplo emblemático diz respeito à consolidação dos serviços substitutivos que atendam aos usuários que façam uso prejudicial de álcool e outras drogas.

As autoras Passos e Portugal (2015) ressaltam que tal questão é acentuada pelas divergências existentes entre duas políticas públicas: a Política do Ministério da Saúde para a Atenção Integral a Usuários de Álcool e outras Drogas e a Política Pública sobre Drogas da Secretaria Nacional de Políticas sobre Drogas do Ministério da Justiça, configurando duas perspectivas: a proibicionista e a antiproibicionista. No contexto de crise econômica de hegemonia neoliberal, as políticas sociais são conduzidas a partir da compreensão referente aos gastos sociais como uma das causas de um Estado inchado e dispendioso, incapaz de fazer frente às demandas de estabilização econômica que, nessa perspectiva, promoveria o bem comum.

Assim, de acordo com Gomes (2015), determinados gastos são considerados excessivos e nocivos, pois desmobilizariam as iniciativas dos indivíduos em se tornar cada vez mais produtivos, sendo a redução do Estado percebida como sinônimo de administração racional e eficiente.

Dessa forma, Woerner (2015) analisa o trabalho profissional do assistente social junto aos que fazem uso prejudicial de álcool e outras drogas e os seus familiares. Essa intervenção, desenvolvida em diversos espaços ocupacionais e modalidades de atendimento, demanda que os profissionais deem respostas às situações atuais. Destacase que os usos de drogas estão relacionados com a atual condição e modo de organização da sociedade capitalista, frente à crescente acumulação de capital, precarização das condições de trabalho, ausência de proteção efetiva por parte do Estado, insegurança e vulnerabilidade.

A rede de serviços disponível para o campo de álcool e drogas, contemplando ações intersetoriais se ampliou. No entanto, mesmo com a ampliação do modelo psicossocial e o crescimento do número de CAPS, houve retrocessos dentro da política de saúde mental, álcool e outras drogas. Como exemplo, pode-se citar a entrada das CT, no contexto da RAPS, definidas como "[...] serviço de saúde destinado a oferecer cuidados contínuos de saúde, de caráter residencial transitório” (BRASIL, 2011, não paginado). Nesse sentido, fica a critério dos CAPS, a possibilidade de encaminhamento dos usuários para as CT, bem como a interlocução dessas com a atenção básica. Assim, as CT passam a funcionar de forma articulada à rede de saúde da região. De acordo com Woerner (2015), os CAPS e as CT não são concorrentes, mas complementares. 
As análises críticas aumentam a partir dos artigos referentes ao ano de 2017, tratando os dados de realidade sobre os movimentos de resistência diante do desmonte e da contrarreforma na política de saúde mental brasileira, constitutiva, portanto, do contexto político, enfrentado no Brasil, com o golpe civil-midiático-jurídico (MIGUEL, 2019) que ascende Michel Temer à presidência.

Nesse sentido, Martins et al. (2017) e Passos (2017) evidenciam o fim do manicômio como possibilidade na luta de classes. Assim, é necessário aproximar o debate da condição das trabalhadoras negras, atuantes na ocupação de cuidadoras, no contexto da política de saúde mental, pois estão vinculadas às desigualdades de classe e raça existentes na realidade brasileira.

Nos anos 2018 e 2019, acirram-se as articulações com setores conservadores, ampliando a contrarreforma na política de saúde mental. Os artigos de Pereira e Guimarães (2018) e Gomes (2018), retomando o processo de formação sócio-histórica do Brasil, apontam, como elemento crucial para compreensão do contexto atual, a questão da cidadania do sujeito com transtorno mental. A reparação histórica das injustiças acometidas contra esse sujeito exige não apenas a criação de políticas públicas e serviços, mas a necessidade de superar a lógica manicomial.

Importante ressaltar, em março de 2018, o assassinato da ativista, mulher, negra, bissexual e vereadora do Rio de Janeiro pelo PSOL, Marielle Franco. O extermínio representou a tentativa de silenciamento dos mais diversos segmentos que buscam ocupar e disputar os espaços e representações. Passos (2018) contribui para construir uma crítica na articulação entre gênero, raça e classe, em particular, a partir dos dados de uma pesquisa nacional sobre uso de crack realizada pela Fundação Oswaldo Cruz. A autora aponta que a maioria das mulheres nesse contexto não são brancas e representam $78,56 \%$ das identificadas, sendo que $51,61 \%$ informaram que 30 (trinta) dias antes da entrevista estavam em situação de rua. As reflexões apontam para o racismo e o patriarcado, que por serem estruturantes e interseccionalizados com a organização econômica, não podem estar descolados da classe social.

O destaque da autora refere-se às instituições de violência como funcionais para a reprodução das desigualdades e opressões, vez que realizam o controle dos corpos, comportamentos e subjetividades. Assim, a naturalização da violência institucional sobre os corpos negros compõe o modelo manicomial. Passos (2018) afirma que são atendidos nos CAPS, majoritariamente, negros (pretos e pardos) e que os retrocessos não podem ser pensados de forma isolada, pois atingem diretamente essa população atendida, que também enfrenta ações truculentas e de violação. Nesse sentido, é a população negra e pobre que sofrerá com o retorno do modelo manicomial, dado que compõe a maioria da população brasileira.

De forma geral, os artigos analisados apresentam a grave crise política e apontam os riscos e ameaças, como o fortalecimento do movimento de retomada do modelo hospitalocêntrico, das práticas religiosas como meio de lidar com a questão das drogas e das violações de direitos humanos (ALVARENGA; SILVEIRA; TEIXEIRA, 2018) aos usuários em geral. Observa-se o aprofundamento dos retrocessos quanto às diretrizes e 
objetivos que fundamentaram a RAPS, particularmente, no campo da atenção aos usuários de álcool e outras drogas.

Segundo Prudencio e Senna (2018), o retorno à lógica hospitalar, reforçado pelo incentivo financeiro, por meio do qual é garantido pagamento integral de procedimentos e reajustes de valores de diárias para ampliação de leitos psiquiátricos em hospitais gerais, representa o retrocesso ao manicômio disfarçado de leitos psiquiátricos. Nesse contexto, tem-se o aprofundamento da medicalização, reforçando a patologização em saúde mental, com relevância do trato diagnóstico específico para o tratamento medicamentoso como caminho exclusivo para o cuidado. Assim, configurase a contrarreforma, com medidas neoliberais, acirrada pelo neoconservadorismo. De acordo com Farias (2019), de um lado, lucra-se imensamente com a loucura e as drogas, a partir das internações e, no caso da última, com a ilicitude; e, de outro, a moralização dessas questões, numa perspectiva de higienização social, legitimada pelo moralismo conservador, potencializando lucros e violando direitos.

Miranda et al. (2019) e Costa (2019) afirmam sobre a necessidade de pensar no avanço do conservadorismo no Brasil. O desmonte do SUS, em detrimento dos ajustes econômicos, tem fortemente impactado a política de saúde mental, assim como as discussões políticas, econômicas e sociais na atualidade. Em relação à participação popular, esta é fundamental, sobretudo, o engajamento dos que são alvo dessa política. A contrarreforma na política de saúde e na saúde mental, álcool e outras drogas vêm correspondendo aos ditames do capital financeiro internacional, estando o país representado por um Estado ultraconservador e de extrema-direita.

O retrocesso em curso está implicado numa análise de totalidade, que não se pode desconsiderar, pois é incisivo como resultado de um processo de financeirização e mundialização do capital, com influência de organismos internacionais direcionando uma agenda de desmonte das políticas e dos direitos por parte do Estado.

De acordo com o estudo empreendido, o retrocesso da política de saúde mental, álcool e outras drogas é estrutural. Essa tendência se coloca articulada com o crescimento do conservadorismo, do moralismo e das crises, em particular, da sanitária que implicam a violação de direitos, principalmente, daqueles que ainda lutam, nesse país, por cidadania, trabalho e dignidade humana.

\section{Conclusão}

São evidentes, neste estudo, a partir da revisão integrativa, os avanços e retrocessos da política pública de saúde mental, álcool e outras drogas no Brasil, em particular, quando se localizam, a partir de 2015, os marcos fundantes na nova configuração política do Estado brasileiro, apontando para a contrarreforma nesse campo.

Observou-se, na análise empreendida, as tendências à remanicomialização da nova política de saúde mental e drogas, colocando em risco o cuidado integral contínuo e em liberdade, o orçamento público para o setor e as relações, condições e processos de trabalho. $\mathrm{O}$ atual contexto, com perspectivas ultraconservadoras, no âmbito da gestão 
pública, impõe a prevalência do saber-poder médico, a expansão da indústria farmacêutica e a centralidade nos hospitais psiquiátricos.

No atual momento, o projeto político em curso, no governo federal, reforça as fragilidades estruturais do próprio SUS e do Estado Democrático de Direito construídos nas últimas décadas. As resistências, portanto, colocam-se como possibilidade e necessidade, pois o enfrentamento e os desafios que se colocam frente ao cenário político, econômico e sanitário devem ser pautados de forma coletiva e potente.

Dessa forma, vislumbra-se fortalecer a participação popular, integrando e aproximando dos movimentos sociais, organizações políticas, redes e coletivos, não endógenos, no campo da saúde mental e drogas. É necessário articular com as demais organizações de luta da sociedade civil, que discutem outros marcadores sociais de diferença, no sentido de se ampliar com as diversas frentes possíveis, para, assim, fortalecer uma política de saúde mental que atenda, de fato, aos sujeitos coletivos em seus modos de (r)existência política, afetiva e social.

\section{Referências}

ALVARENGA, R.; SILVEIRA, J. I.; TEIXEIRA, D. da. S. G. Política de drogas no Brasil no cenário de violações aos direitos humanos. Argumentum, Vitória, v. 10, n. 3, p. 123-136, ago./dez. 2018. Doi https://doi.org/10.18315/argumentum.v1oi3.20841. Disponível em: https://periodicos.ufes.br/argumentum/article/view/20841. Acesso em: 11 fev. 2020.

AMARANTE, P.; NUNES, M. de O. A reforma psiquiátrica no SUS e a luta por uma sociedade sem manicômios. Ciência \& Saúde Coletiva, n. 23, v. 6, p. 2067-2074, 2018.

ARAGÃO. I.; ROSA. L. C. D. S. Política sobre drogas e neoliberalismo: comunidades terapêuticas e debate no Serviço Social. Temporalis, Brasília (DF), ano 19, n. 37, p. 222238, jan./jun. 2019. Doi 10.22422/temporalis.2019v19n37p222-238. Disponível em: https://periodicos.ufes.br/temporalis/article/view/24061. Acesso em: 21 fev. 2020.

BRASIL. Emenda Constitucional no 95, de 15 de dezembro de 2016. Altera o Ato das Disposições Constitucionais Transitórias, para instituir o Novo Regime Fiscal, e dá outras providências. Brasília (DF), 15 dez. 2016a. Disponível em http://www.planalto.gov.br/ccivil_03/constituicao/emendas/emc/emc95.htm. Acesso em: 20 mar. 2020.

BRASIL. Presidência da República. Decreto no 9.674, de o2 de janeiro de 2019. Brasília (DF), 2019a. Disponível em: http://www.planalto.gov.br/ccivil_03/_ato20192022/2019/decreto/D9674.htm. Acesso em: 21 fev. 2020.

BRASIL. Presidência da República. Decreto no 7.179, de 20 de maio de 2010. Diário Oficial da União, Brasília (DF), 2010. Seção 1. Disponível em: http://www.planalto.gov.br/ccivil_03/_Ato2007-2010/2010/Decreto/D7179.htm. Acesso em: 20 fev. 2020. 


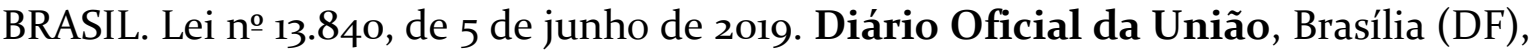
2019b. Seção 1. Disponível em: http://www.planalto.gov.br/ccivil_03/_ato20192022/2019/lei/L13840.htm. Acesso em: 20 mar. 2020.

BRASIL. Lei Federal no 10.216, de 6 de abril de 2001. Dispõe sobre a proteção e os direitos das pessoas portadoras de transtornos mentais e redireciona o modelo assistencial em saúde mental. Diário Oficial da União, Brasília (DF), 2001. Seção 1. Disponível em: http://www.planalto.gov.br/ccivil_o3/leis/leis_2001/110216.htm. Acesso em: 21 mar. 2020.

BRASIL. Ministério da Saúde. Nota Técnica no 11, de o4 de fevereiro de 2019. Brasília (DF), 2019c. Disponível em: http://pbpd.org.br/wp-

content/uploads/2019/02/o656ad6e.pdf. Acesso em: 11 fev. 2020.

BRASIL. Ministério da Saúde. Portaria GM/MS no 3.588, de 21 de dezembro de 2017. Altera as Portarias de Consolidação no 3 e no 6, de 28 de setembro de 2017, para dispor sobre a Rede de Atenção Psicossocial, e dá outras providências. Brasília (DF), 22 dez. 2017. Disponível em:

http://bvsms.saude.gov.br/bvs/saudelegis/gm/2017/prt3588_22_12_2017.html. Acesso em: 10 fev. 2020.

BRASIL. Ministério da Saúde. Portaria SAS/MS no 1.482, de 25 de outubro de 2016. Inclui na Tabela de Tipos de Estabelecimentos de Saúde do Cadastro Nacional de Estabelecimentos de Saúde - CNES o tipo 83 - Polo de Prevenção de Doenças e Agravos de Promoção da Saúde. Brasília (DF), 25 out. 2016b. Disponível em: http://bvsms.saude.gov.br/bvs/saudelegis/sas/2016/prt1482_25_10_2016.html. Acesso em: 20 mar. 2020.

BRASIL. Ministério da Saúde. Portaria GM/MS no 3.o88, de 23 de dezembro de 2011. Diário Oficial da União. Brasília-DF, 2011. Seção 1. Disponível em: http://bvsms.saude.gov.br/bvs/saudelegis/gm/2011/prt3088_23_12_2011_rep.html. Acesso em: 20 mar. 2020.

BRASIL. Ministério da Saúde. Portaria GM/MS no 336, de 19 de fevereiro de 2002. Diário Oficial da União, Brasília (DF), 2002. Seção 3. Disponível em: https://bvsms.saude.gov.br/bvs/saudelegis/gm/2002/prt0336_19_02_2002.html. Acesso em: 21 fev. 2020.

COSTA, T. C. R. da. A política de saúde mental na atualidade e o avanço do conservadorismo. Argumentum, Vitória, v. 11, n. 2, p. 163-178, mai./ago. 2019. Doi 10.18315/argumentum.vi1i2.20848. Disponível em: https://periodicos.ufes.br/argumentum/article/view/20848. Acesso em: 11 fev. 2020.

DUARTE, M. J. de O. Política de saúde mental e drogas: desafios ao trabalho profissional em tempos de resistência. Revista Libertas, Juiz de Fora, v.18, n.2, p. 227243, ago./dez. 2018. 
FARIAS, L. L. Estado, contrarreforma e as políticas de saúde e saúde mental no Brasil. Argumentum, Vitória, v. 11, n. 3, p. 47-66, set./dez. 2019. Doi 10.18315/argumentum.vi1i3.22727. Disponível em: https://periodicos.ufes.br/argumentum/article/view/22727. Acesso em: 11 fev. 2020.

GOMES, T. Capitalismo contemporâneo, crise e política social: impactos na política de saúde mental, crack, álcool e outras drogas. O Social em Questão, Rio de Janeiro, ano 18, n. 34, p. 297-314, jul./dez. 2015.

GOMES, T. M. da S. Reforma psiquiátrica e formação sócio-histórica brasileira: elementos para o debate. Argumentum, Vitória, v. 10, n.3, p. 24-34, set./dez. 2018. Doi 10.18315/argumentum.vioi3.21691. Disponível em:

https://periodicos.ufes.br/argumentum/article/view/21691. Acesso em 11 fev. 2020.

GUIMARÃES, T. de A. A.; ROSA, L. C. dos S. A remanicomialização do cuidado em saúde mental no Brasil no período de 2010-2019: análise de uma conjuntura antirreformista. O Social em Questão, Rio de Janeiro, ano 22, n. 44, p. 111-138, maio/ago. 2019.

HEIDRICH, A. V. Balanço da reforma psiquiátrica antimanicomial brasileira. In: DUARTE, M. J. de O. et. al. (Org.). Serviço Social, Saúde Mental e Drogas: políticas públicas e direitos humanos. Campinas: Papel Social, 2017.

JACKSON, G. B. Methods for integrative reviews. Review of educational research fall, v. 5o, n. 3, p. 438-46o, 1980.

MARTINS, B. A.; COELHO, D. A.; PEREIRA, M. de O.; PASSOS, R. G. (Ainda) Por uma sociedade sem manicômios: experiências do Núcleo Estadual da Luta Antimanicomial do Rio de Janeiro. O Social em Questão, Rio de Janeiro, ano XX, n. 37, p. 221-228, jan./abr. 2017.

MIGUEL, L. F. O colapso da democracia no Brasil: da Constituição ao golpe de 2016. São Paulo: Expressão Popular, Fundação Rosa Luxemburgo, 2019.

MIRANDA, S. de A. B.; ROCHA, L. A.; MATOS, R. K. DE S.; MARTINS, L. H. S. Loucos, drogados e associados: participação social no campo da saúde mental em tempos austeros. O Social em Questão, ano 22, n. 44, p. 213-240, maio/ago. 2019.

PASSOS, R. G. Holocausto ou Navio Negreiro?: inquietações para a reforma psiquiátrica brasileira. Argumentum, Vitória, v. 10, n. 3, p. 10-22, set./dez. 2018. Doi 10.18315/argumentum.vioi3.21483. Disponível em: https://periodicos.ufes.br/argumentum/article/view/21483. Acesso em: 11 fev. 2020.

PASSOS, G. R. “De escravas a cuidadoras”: invisibilidade e subalternidade das mulheres negras na política de saúde mental brasileira. O Social em Questão, Rio de Janeiro, ano 20, n. 38, p. 77-94, maio/ago. 2017. 
PASSOS, R. G.; PORTUGAL, S. Breve balanço da política de saúde mental: análise comparativa Brasil e Portugal a partir da experiência das residências terapêuticas. Revista de Políticas Públicas, São Luís, v. 19, n. 1, p. 91-102, jan./jun. 2015.

PEREIRA, S. L. B.; GUIMARÃES, S. de J. Repensando a cidadania e a justiça para a pessoa com transtorno mental: olhares a partir das teorias de Marshall e Fraser. Textos \& Contextos, Porto Alegre, v. 17, n. 2, p. 393 - 405, ago./dez. 2018

PINHO, L. Saúde mental: contra-reforma? RADIS - Comunicação e Saúde, Rio de Janeiro, edição n. 196, p. 6, 1 jan. 2019. Disponível em: https://radis.ensp.fiocruz.br/index.php/home/noticias/saude-mental-contra-reforma. Acesso em: 28 mai. 2020.

PITTA; A. M. F.; GULJOR, A. P. A violência da contrarreforma psiquiátrica no Brasil. Cadernos do CEAS, Salvador, Recife, n. 246, p. 6-14, jan./abr. 2019.

PRUDENCIO; J. D. L. SENNA; M. de C. M. Retrocessos na atenção a usuários de álcool e outras drogas. Argumentum, Vitória, v. 10, n. 3, p. 79-93, set./dez. 2018. Doi 10.18315/argumentum.v10i3.20854. Disponível em: https://periodicos.ufes.br/argumentum/article/view/20854. Acesso em 11 fev. 2020.

REVADAM, R.; SCARTEZINI, T. 50 anos em 5: como o Brasil está regredindo décadas na luta antimanicomial. ComCiência - Revista Eletrônica de Jornalismo Científico (Dossiê 214: Saúde Mental), Campinas: Labjor-Unicamp; SBPC; Fapesp, fev. 2020. Disponível em: http://www.comciencia.br/50-anos-em-5-como-o-brasil-estaregredindo-decadas-na-luta-antimanicomial/. Acesso em: 20 fev. 2020.

SILVA, E. S. da.; MOURA, V. G. G. de. Crise capitalista e política de saúde pública: tendências atuais pertinentes à saúde mental brasileira. Revista de Políticas Públicas, São Luís, v. 19, n. 1, p. 103-115, jan./jun. 2015.

SOUZA, M. T.; SILVA, M. D.; CARVALHO, R. Revisão integrativa: o que é e como fazer. Einsten, v. 1, n. 8, p. 102-106, 2010.

TENÓRIO, F. A reforma psiquiátrica brasileira, da década de 1980 aos dias atuais: história e conceito. História, Ciências, Saúde Manguinhos, Rio de Janeiro, v. 9, n. 1, p. 25-59, jan./abr. 2002.

WOERNER, C. B. Serviço social e saúde mental: atuação do assistente social em comunidade terapêutica. Textos \& Contextos, Porto Alegre, v. 14, n.1, p. 174-185, jan./jun. 2015. 
Lara Rodrigues CAPUTO Trabalhou na concepção e delineamento do artigo, na pesquisa documental e bibliográfica, na análise e interpretação dos dados, na redação do artigo e, por fim, na sua revisão crítica. Mestranda do Programa de Pós-Graduação de Serviço Social da UFJF (turma 2019-2021), com participação no GEDIS:Grupo de Estudos e Pesquisas em Sexualidade, Gênero, Diversidade e Saúde: Políticas e Direitos, também da UFJF. Graduada em Serviço Social pela Universidade Federal de Juiz de Fora em março de 2017. Durante a graduação participou de projetos de Iniciação Científica, Extensão e Monitoria, todos eles relacionados à temática "Classes e Movimentos Sociais".

Marciléa TOMAZ Trabalhou na concepção e delineamento do artigo, na pesquisa documental e bibliográfica, na análise e interpretação dos dados, na redação do artigo e, por fim, na sua revisão crítica. Possui graduação em Serviço Social pela Universidade Federal de Juiz de Fora (2016). Especialização na modalidade de residência multiprofissional em Saúde Mental pelo Hospital Universitário/UFJF (2018). Especialista em Relações de gênero e sexualidades: perspectivas interdisciplinares pela Universidade Federal de Juiz de Fora, UFJF, Brasil (2019). Mestranda em Serviço Social pelo Programa de Pós-Graduação em Serviço Social da Universidade Federal de Juiz de Fora (Previsão de Término 2021).

Vanisse Bernardes BEDIM Trabalhou na concepção e delineamento do artigo, na pesquisa documental e bibliográfica, na análise e interpretação dos dados, na redação do artigo e, por fim, na sua revisão crítica. Graduada em Serviço Social pela Universidade Federal de Juiz de Fora (2012 - 2016). Pós-graduada em "Instrumentalidade do Serviço Social com ênfase em: Saúde, Assistência Social, Educação e Poder Judiciário", pela Unesav ? Unidade de Ensino e Aprendizado de Viçosa (2016-2018). Em fevereiro de 2019 concluí a pósgraduação, modalidade lato sensu, através da inserção na Residência Multiprofissional do HU/UFJF (20172019), Programa de Saúde Mental. Mestranda em Serviço Social, pela UFJF.

Marco José de Oliveira DUARTE Trabalhou na concepção e delineamento do artigo, na orientação da pesquisa documental e bibliográfica, na análise e interpretação dos dados, na redação do artigo, na sua revisão crítica e, por fim, aprovação da versão a ser publicada.

Pós-Doutor em Politicas Sociais e Cidadania na Universidade Católica do Salvador (2016); Doutor em Serviço Social pela Universidade do Estado do Rio de Janeiro (2012); Mestre em Serviço Social pela Universidade Federal do Rio de Janeiro (1993); Residência em Serviço Social (Saúde Comunitária) do Hospital Universitário Pedro Ernesto da Universidade do Estado do Rio de Janeiro (1989); Cursou as disciplinas do Curso de Doutorado em Saúde Coletiva da Universidade Estadual de Campinas (1998 - 2001), tornando Especialista em Saúde Coletiva. Possui graduação em Serviço Social (1986) e em Psicologia (1987) pela Universidade Federal Fluminense. 